\title{
The Quality of Life - An Indicator of Fair Treatment of Allergic Rhinitis
}

\author{
Genel Sur ${ }^{1,2 *}$, Floca Emanuela ${ }^{1}$, Valer Donca ${ }^{1,3}$ and Talu (Nicoara) Simona ${ }^{1,4}$ \\ ${ }^{1}$ University of Medicine and Pharmacy, Iuliu Hatieganu, Cluj-Napoca, Romania \\ ${ }^{2}$ Emergency Clinical Hospital for Children, Cluj-Napoca, Romania \\ ${ }^{3}$ Municipal Hospital, Cluj Napoca, Romania \\ ${ }^{4}$ Ophthalmology Clinic, Cluj-Napoca, Romania
}

\begin{abstract}
The current concept of quality of life reported to health status is described by patients in relation to personal expectations. These expectations vary over time and are influenced by the duration and severity of disease, the limitations of any kind, and family support. Quality of life is measured using individual questionnaires. These questionnaires are multidimensional and cover multiple aspects such as physical condition, emotional, social and cognitive status. Other aspects of the questionnaire refer to the individual's status in society and the perception of sickness.

The purpose of this study was to estimate the quality of life of patients with allergic rhinitis and to establish the best treatment. To assess quality of life we used five symptoms score and visual analog scale.

We have studied 92 cases with allergic rhinitis. Patients included in the study were between 6 and 18 years Patients completed questionnaires that reflect quality of their life. Depending on the severity of symptoms patients were divided into two groups: patients with mild persistent allergic rhinitis $(22 \%)$ and patients with moderate-severe persistent allergic rhinitis (78\%).
\end{abstract}

Keywords: Quality of Life; Child; Treatment

\section{Introduction}

Allergic rhinitis is an inflammatory disease of the nasal mucosa caused by immunoglobulins-E mediated reaction to various allergens. Although allergic rhinitis is a common disease, its increasing prevalence, association with other factors of allergic march and impact on quality of life can not be underestimated [1-4].

Prevalence of allergic rhinitis is increasing in developed countries and varies between $10 \%$ and $20 \%$. Allergic rhinitis is a component of the allergic march; so it is frequently associated with atopic dermatitis, urticaria and allergic asthma but also with upper airway inflammation (otitis media, sinusitis) [5,6]. Clinical manifestations of allergic rhinitis include rhinorrhea, nasal obstruction, nasal itching, sneezing and itchy eyes. Sometimes symptoms are clear, these typically occur after exposure to an allergen which can be identified by the patient or parents. Sometimes the clinical manifestations are minor and therefore the patient consult a doctor only when symptoms worsen because the child has accommodated them. Depending on the chronicity and severity of the symptoms allergic rhinitis was divided into four categories: mild intermittent, severe intermittent, mild persistent, and severe persistent. Allergic rhinitis at children leads to a variety of issues that affect quality of life. The quality of life is severely compromised by frequent night awakenings, easy fatigue, irritability, and defects of language. It can affect both school and social activities $[5,6]$.

The current concept of quality of life in relation to health recognizes that subjects describe their health status in relation to personal expectations. Quality of life is currently measured using individual questionnaires that are multidimensional and covers aspects of physical, social, and emotional condition, and those related to work and the disease itself. To assess quality of life are used two questionnaires: Visual Analogue Scale (VAS) and Quality of Life Questionnaire (RQLQ). Visual analog scale is a quantitative method used to assess the severity of rhinitis. Quality of Life Questionnaire, a tool for assessing the severity of rhinitis was developed by Juniper EF et al. to quantify the functional problems (physical, emotional, social and occupational).
The score of five symptoms evaluates the intensity of rhinorrhea, itching, nasal obstruction, sneezing and ocular itching. The total score of symptoms is obtained by summing the scores of symptoms. A score over 6 defines moderate-severe allergic rhinitis.

Diagnosis of allergic rhinitis is based on a thorough history to highlight the symptoms, frequency of exacerbations, aggravating factors and exposure to allergens. For the diagnosis of allergic rhinitis, various studies are helpful including the following: skin-prick testing, allergen-specific IgE testing, and serum IgE $[7,8]$

The most currently available therapeutic measures are: avoidance of allergens, oral and intranasal antihistamines, intranasal corticosteroids, nasal decongestants, leukotriene receptor antagonists, and allergenspecific immunotherapy. Treatment of patients should be given by the onset of symptoms and it should significantly improve quality of life. Currently this treatment must be customized to each patient. In the same time this treatment should be done gradually, depending on the severity symptoms [9-11].

\section{Material and Methods}

The study was performed on a total of 92 cases admitted to a university children's hospital in the period between 1 July 2012 and 30 June 2014. Patients were aged between 6 and 18 years. We performed a prospective observational study. Medical records contain written consent of the parents regarding investigations and therapy.

*Corresponding author: Genel Sur, University of Medicine and Pharmacy, luliu Hatieganu, Cluj-Napoca, Romania, Tel: 400724504964; E-mail: surgenel@yahoo.com

Received August 29, 2014; Accepted December 15, 2014; Published December 20, 2014

Citation: Sur G, Emanuela F, Donca V, (Nicoara) Simona T (2014) The Quality of Life - An Indicator of Fair Treatment of Allergic Rhinitis. J Allergy Ther 5: 202. doi:10.4172/2155-6121.1000202

Copyright: (c) 2014 Sur G, et al. This is an open-access article distributed unde the terms of the Creative Commons Attribution License, which permits unrestricted use, distribution, and reproduction in any medium, provided the original author and source are credited. 
The following criteria should be compelled for inclusion in the study:

- confirmed diagnosis of persistent allergic rhinitis

- aged between 6 and 18 years

- written consent of the parent

Exclusion criteria are:

- Presence of upper respiratory infections in the last month

- Presence of obstructive lung infections

- Chronic respiratory diseases

- Cardiovascular disease

- Known chronic infections

- Mental illness

- Known malignancy

- Inflammatory connective tissue

Statistical processing was performed by Student's t-test: TwoSample Assuming Unequal Variances and estimating p-value to correlate the different measurements on the same group of patients, the threshold of statistical significance was 0.05 .

Patients diagnosed with allergic rhinitis completed a questionnaire to assess quality of their life. The score of five symptoms assessed rhinorrhea, nasal itching, nasal obstruction, sneezing, and eye congestion.

Patients have rated their symptoms on a scale from 0 to 3 (0-absence of symptoms, 1-mild symptoms without disturbing, 2-moderate symptoms, disturbing, without affecting daily activities, 3-severe symptoms that affect daily activities and sleep). Classification of severity score was done according to ARIA guidelines. Score was determined by summing the values obtained for each symptom. Patients with total symptom score less than or equal to 6 were in the group with mild persistent allergic rhinitis and those with a score above 6 in the group with moderate-severe persistent allergic rhinitis. Visual analog scale is a quantitative method for assessing allergic rhinitis. Using this method, patients were assessed sleep quality on a scale from 0 to 10 (0-do not sleep, 10-sleep well). This method is used both for assessing quality of life and the therapeutic efficiency. Patients received treatment according to the severity of symptoms. Patients with moderate-severe persistent allergic rhinitis received second generation antihistamines associated with intranasal corticosteroids and nasal decongestants by short periods. Patients with mild persistent allergic rhinitis received antihistamines second generation with or without nasal decongestants by short periods. Few of them received leukotriene inhibitors. Symptom score was assessed to study admission. The next step was establishing individualized treatment according to the symptoms' severity. Two months after the initiation of therapy patients were reviewed.

\section{Results}

Regarding the sex distribution of patients $56 \%$ of the cases were girls and $44 \%$ were boys. $38 \%$ of patients come from rural areas and the rest of $62 \%$ from urban areas. Regarding living conditions $20 \%$ of parents indicated that they have pets (dog or cat).

Depending on severity score, patients were divided into two groups: $22 \%$ of patients with mild persistent allergic rhinitis and $78 \%$ of cases with moderate-severe persistent allergic rhinitis.
Patients were reassessed at 2 months, at which time they mentioned evolution of symptoms from the first week of treatment. Analysis of clinical manifestations during the two months of treatment showed a favorable evolution from the early days after of therapy. In case of exacerbations patients knew which medication must be administered.

Symptoms of patients were significantly improved in the first week of treatment. After the first week of treatment, $83 \%$ of the 72 patients with moderate-severe persistent allergic rhinitis recognized a net improvement of symptoms, with a good quality of life without affecting daily activities and sleep. $10 \%$ of the 72 patients with moderatesevere persistent allergic rhinitis continued to maintain the source of allergens (cats and dogs) in the living environment. Other 5 patients, representing $7 \%$ of those with the moderate-severe form of disease have not regularly administered treatment, being without family support. All patients with mild persistent allergic rhinitis had favorable evolution after the first week of treatment.

\section{Discussions}

In our study most cases were with moderate-severe persistent allergic rhinitis because as long as symptoms were mild patients have not consulted a healthcare service $[1,12]$. The treatment with secondgeneration antihistamines combined or not to steroids and decongestants quickly led to improvement of symptoms in the first week of treatment [13]. Failure to eliminate allergens from the living environment of the patient causes persistence of symptoms despite the proper treatment. Patients who have been continued to live with pets presented symptoms even if they have given treatment. The questionnaires used in the study allowed us to evaluate both the severity of symptoms and the response to treatment, and finally allowed us to appreciate patients' quality of life.

Quality of life is influenced by a number of individual factors so that each patient has a particular perception of symptoms. The quality of life is very important in the classification of allergic rhinitis severity. The Bosquet study demonstrates that visual analog scale method can be used to assess the severity of allergic rhinitis [14]. Another study conducted in France show that all stages of sleep are disturbed in patients with allergic rhinitis. Uncontrolled symptoms of allergic rhinitis induce decreased quality of life. Kay reports that in USA allergic rhinitis causes 3.5 million days of absences from work and 2 million days of absences from school [15]. For these reasons allergic rhinitis is a health issue with economic and social implications.

\section{Conclusions}

Patients' quality of life depends on the time of diagnosis, the promptitude of establishing treatment and allergen avoidance.

Moderate-severe persistent allergic rhinitis significantly affects the quality of life.

The quality of life is more affected as well as the total score of symptoms is higher.

\section{References}

1. Brozek JL, Bousquet J, Baena-Cagnani CE, Bonini S, Canonica GW, et al (2010) Allergic Rhinitis and its Impact on Asthma (ARIA) guidelines: 2010 revision. J Allergy Clin Immunol 126: 466-476.

2. Turner PJ, Kemp AS (2012) Allergic rhinitis in children. J Paediatr Child Health 48: $302-310$

3. Miraglia Del Giudice, Marseglia A, Leonardi S et al (2011) Allergic rhinitis and quality of life in children. Int J Immunopathol Pharmacol 24: 25-28.

4. Colás C, Galera H, Añibarro B, Soler R, Navarro A, et al. (2012) Disease severity impairs sleep quality in allergic rhinitis (The SOMNIAAR study). Clin Exp Allergy 42: 1080-1087. 
Citation: Sur G, Emanuela F, Donca V, (Nicoara) Simona T (2014) The Quality of Life - An Indicator of Fair Treatment of Allergic Rhinitis. J Allergy Ther 5: 202. doi:10.4172/2155-6121.1000202

Page 3 of 3

5. Sur Genel, Emanuela Floca, Lucia Sur (2013) Food Allergy: Always a Threat, How do We Treat it? Pharmaceut Anal Acta 4

6. Sur Genel, Floca Emanuela, Lucia Sur et al. (2012) Therapeutic Perspectives on the Treatment of Urticaria Associated with Angioedema. Pharmaceut Anal Acta 3.

7. Greiner AN, Hellings PW, Rotiroti G, Scadding GK (2011) Allergic rhinitis. Lancet 378: 2112-2122.

8. Wallace DV, Dykewicz MS, Bernstein DI, Blessing-Moore J, Cox L, et al. (2008) The diagnosis and management of rhinitis: an updated practice parameter. $\mathrm{J}$ Allergy Clin Immunol 122: S1-84.

9. Bachert C, Maspero J (2011) Efficacy of second-generation antihistamines in patients with allergic rhinitis and comorbid asthma. J Asthma 48: 965-973.
10. Dalia H. El-Ghoneimy (2012) Antihistamines in pediatric allergy. Egypt J Pediatr Allergy Immunol 10:3-12.

11. Rachelefsky G, Farrar JR (2013) A control model to evaluate pharmacotherapy for allergic rhinitis in children. JAMA Pediatr 167: 380-386.

12. Meltzer EO, Gross GN, Katial R, Storms WW (2012)Allergic rhinitis substantially impacts patient quality of life: findings from the Nasal Allergy Survey Assessing Limitations. J Fam Pract 61: S5-10.

13. González-Núñez V, Valero AL, Mullol J (2013) Impact of sleep as a specific marker of quality of life in allergic rhinitis. Curr Allergy Asthma Rep 13: 131-141.

14. Bousquet PJ, Combescure C, Neukirch F, Klossek JM, Méchin H et al. (2007) Visual analog scales can assess the severity of rhinitis graded according to ARIA guidelines. Allergy 62: 367-372.

15. Kay GG1 (2000) The effects of antihistamines on cognition and performance. J Allergy Clin Immunol 105: S622-627. 